\title{
How Burnout Affects Turnover Intention? The Conditional Effects of Subjective Vitality and Supervisor Support
}

\author{
Meral ELÇí ${ }^{1}$, Bora YILDIZ ${ }^{2 *}$, Melisa ERDÍLEK KARABAY ${ }^{3}$ \\ ${ }^{1}$ Gebze Technical University, Faculty of Business Administration, Department of Management, Gebze, Kocaeli- \\ TURKEY \\ ${ }^{2}$ Istanbul University, Faculty of Economics, Department of Management, Beyazit, Istanbul-TURKEY \\ ${ }^{3}$ Marmara University, School of Banking and Insurance, Department of Insurance, Göztepe, Istanbul-TURKEY
}

\section{Keywords: \\ Burnout, Turnover Intention, Subjective Vitality, Supervisor \\ Support, Emotional Exhaustion \\ Depersonalization}

\section{Received}

21 May 2016

Received in revised form 12 April 2018

Accepted

21 May 2018

Correspondence:

borayildiz@istanbul.edu.tr

\begin{abstract}
Although numerous researchers in the literature have tried to show that low levels of supervisory support contributing to job burnout and turnover, the moderating effects of supervisor support and subjective vitality on this interaction still keep unclarified. This paper examines the effect of burnout on turnover intention of 295 employees, who are employed in Turkish health sector. It is also aimed whether supervisor support and subjective vitality have moderating effects on job burnout-turnover intention relationship. The findings show that the two dimensions of burnout namely emotional exhaustion and depersonalization positively affects turnover intention. Moreover, the moderating effects of supervisor support and subjective vitality on the relationship between burnout (emotional exhaustion and depersonalization) and turnover intention are statistically significant. Specifically, the levels of subjective vitality and supervisor support increases, the burnoutturnover intention relationship gradually strengthens. Managerial applications and further research directions are provided.
\end{abstract}

(C)AIMI Journals

Since employees are considered one of the most important assets of the organization, it is crucial for firms to create a work atmosphere that supports psychological well-being (Charoensukmongkol, Moqbel, \& Gutierrez-Wirsching, 2016). Burnout has long been 
expressed as a contextual determinant of employee outcome in the workplace by numerous researches and it is widely known that it mostly appears as a negative affective response of chronic work stress (Payne, 2001). Recent research shows that burnout can be detrimental to the workforce (Weigl et al., 2016), thus, can have harmful effects on employees' attitudes as well as behaviors.

It is claimed that health service is one of the hardest working places full of stressors. Health sector has been one of the popular field of researches among scholars considering burnout theory and practice (Al-Dubai \& Rampal, 2010; Lasalvia et al., 2009; Özler \& Atalay, 2011; Tarcan, Tarcan, \& Top, 2016; Tselebis, Moulou, \& Ilias, 2001). This is because health care organizations are considered to be suffering financially from increased burn out and turnover intentions such as stress-related diseases and mental problems. In the related literature, various evidence supports the assumptions of negative outcomes of burnout and its interaction with turnover intention (Han, Bonn, \& Cho, 2016; Kim \& Stoner, 2008; Lu \& Gursoy, 2016). In the related literature, evidence supports the assumptions of negative outcomes of burnout and its interaction with withdrawal intentions. Individuals intend turnover decisions through a series of phases in a more or less predictable order (Steel, 2002). A loss of productivity or quality in the workplace can occur if the burnout of individuals is not prevented; consequently, it can lead to individual reductions in morale, psychological or physical health (Pienaar \& Willemse, 2008). This argument is valid in health sector since exhausted and depersonalized staff would have higher levels of turnover intention (Kalliath \& Beck, 2001).

There are many empirical studies on the literature based on social exchange theory (Cropanzano \& Mitchell, 2005) which reveal that perceived supervisor support negatively affects turnover that is one of the negative deviant behaviors (Eisenberger et al., 2002; Khan, Mahmood, Kanwal, \& Latif, 2015; Shanock \& Eisenberger, 2006). Social exchange theory indicates that significant support from supervisors can assist employees to feel closer and affiliated and they return it to the organization, for example by helping their supervisors in acquiring the organizational purposes.

(Weigl et al., 2016). Based on self-determination theory (Niemiec et al., 2010) subjective vitality can be a critical factor of well-being of employees (Ryan \& Frederick, 1997). Despite vitality has been an important research topic when attempting to understand intergroup relations (Abrams, Barker, \& Giles, 2009), there is a scarcity of evidence that demonstrate its effects on employee withdrawal intentions.

To this end, the current study aimed to analyse the employees' behaviours by identifying the moderating effect of subjective vitality and supervisor support on the relationship between burnout and turnover intention.

\section{Burnout and Turnover Intention}

Burnout has been connected with different and diverse forms of job withdrawal; following this, different forms of job withdrawal includes intention to leave the job, actual turnover, and absenteeism (Leiter Michael \& Maslach, 2009). Regarding the significant evidences, turnover intention is more probable to happen for those employees who possess high-degree of burnout in numerous careers (Huang, Chuang, \& Lin, 2003; Shimizu, Feng, \& Nagata, 2005). Research in the organizational literature supports a positive relationship between burnout and turnover 
intention (Cropanzano, Rupp, \& Byrne, 2003; Fogarty, Jagdip, Gray, \& Ronald, 2000; Jones, Norman, \& Weir, 2010). Occupational stress is defined as harmful physical and emotional responses incurred in the work environment. Considering the jobs changing from manufacturing industries to service industries, the psychological and emotional needs of work have expanded, which resulted in great attention to work-related burnout (Tsai, Huang, \& Chan, 2009). Considerable and intense occupational stress and low job satisfaction were connected with high burnout, especially in the emotional exhaustion and depersonalization aspects. Two elements, namely low job satisfaction and high emotional exhaustion were connected with high turnover intention among employees (Lin, Jiang, \& Lam, 2013).

\section{Moderating Effect of Supervisor Support}

Research has demonstrated that supervisor support promotes employees' positive sense of self leading to increased psychological well-being. It is affirmed that organizations seeking to establish healthier work environment should not neglect supervision (Gilbreath \& Benson, 2004). Therefore, the quality of the relationships between subordinates and supervisors could strongly affect potential burnout of employees (Charoensukmongkol et al., 2016). Among strain outcomes we can refer to turnover intention that many studies have supported as a crucial result of burnout (Blanch \& Aluja, 2012; Kim \& Lee, 2009). Despite evidence presenting supervisor support as a buffering variable in the literature (Himle, Jayaratne, \& Thyness, 1989; Karasek, Triantis, \& Chaudhry, 1982; Kickul \& Posig, 2001; Kirmeyer \& Dougherty, 1988; O'Driscoll et al., 2003; Russo \& Waters, 2006; Weigl et al., 2016) there is a limited number of studies which have demonstrated that supervisory support can be a critical buffering variable contributing to burnout and turnover interaction. Choi, Cheong, and Feinberg (2012) in their study investigated whether supervisor support, monetary rewards, and career paths moderated the relationship between job burnout and turnover intentions. The results indicated that the supervisor support worsen the harmful effect of depersonalization on turnover intentions.

\section{Moderating Effect of Subjective Vitality}

In a series of studies, it is acknowledged that subjective vitality combines both physical and psychological factors (Nix et al., 1999; Ryan \& Frederick, 1997) representing positive feeling of aliveness and possessing personal energy (Ryan \& Frederick, 1997). Researchers (Kark and Carmeli, 2009; Nix et al, 1999) have stated that although vitality is a positive emotional state it may have various determinants. It is generally discussed that health-related stressors are expected to affect subjective vitality much more negatively compared to other stressors (Ryan \& Frederick, 1997). Therefore, in this study subjective vitality is considered to be associated with burnout. Despite researches that examined the mediating effect of subjective vitality (Akın, 2012; Allen \& Kiburz, 2012; Kark \& Carmeli, 2009) studies seem to address the moderating effects of vitality.

\section{Conceptual Framework}

\section{Burnout}

Burnout is one of the highly scrutinized negative results (Keel, 1993) that describes a wide range of behaviors and attitudes of employees in high-stress work places (Lee \& Ashforth, 
1996). It has multiple dimensions (Maslach \& Jackson, 1981) which are interrelated and reveal as exhaustion, detachment from the job, a sense of ineffectiveness, and a lack of accomplishment (Lee \& Ashforth, 1996; Pienaar \& Willemse, 2008). Emotional exhaustion can be conceptualized as the first stage of burnout syndrome and defined as a feeling of being emotionally exhausted and overextended by one's work (Wright \& Cropanzano, 2000). Another feature of burnout is named depersonalization, which is understood as an unfeeling and impersonal response in the direction of the recipients of one's care (Payne, 2001). The diminished personal accomplishment of burnout is relatively more complex compared to the other two dimensions. Individuals who experience a lack of professional accomplishment feel that they no longer make any contribution to organization and they are personally unable to meet the requirements of the job (Pienaar \& Willemse, 2008). To this end, it can be reported as the negative feeling of competence and successful acquirement in one's work with people (Maslach \& Jackson, 1981). Burnout may have significant impacts on employees' health such as 1 addiction as well as psychological disorders (Wright \& Cropanzano, 2000). In terms of organizational aspects, job burnout leads to significant consequences like absenteeism, inability in innovative capabilities and productivity as well as intention to leave (Toppinnen-Tanner et al., 2005). In the related literature, studies often indicate that burnout among professionals can be detrimental especially for those working in health sector (Ashtari, Farhady, Khodaee, 2009; Bogaert, Clarke, Willems, \& Mondelaers, 2013; Lazaro, Shinn, \& Robinson, 1984).

\section{Turnover Intention}

Turnover intention is among the popular topics of research in the field of organizational behavior (Ar1, Bal, \& Bal, 2010; Turunç \& Çelik, 2010). Turnover intention is often described as a conscious and keen type of feeling (Tett \& Meyer, 1993). The concept can be expressed as employees thinking about leaving their job's intention due to their dissatisfaction with current working conditions. Intention to leave the job before quitting can be a determinant for the behavior of quitting whereas intention stage can provide guidance to organizations in terms of retaining staff (Ar1, Bal, \& Bal, 2010). The issue of employees' intention to leave still continues to be a major problem area for organizations despite the numerous researches (Porter, Steers, Mowday, \& Boulian, 1973).

\section{Supervisor Support}

So far, the research on the impact of supervisor on employee outcome has predominantly drawn on social exchange theory (Blau, 1964; Rhoades \& Eisenberger, 2002; Salancik \& Pfeffer, 1978; Thomas \& Griffin, 1983). Literature suggests that highly supportive supervisors promote employees' productivity whereas less supportive supervisors are considered as an obstacle to success by employees. Various studies (Babin \& Boles, 1996; Shanock \& Eisenberger, 2006) support the claim that supervisors are people that have a powerful influence on employees. This is mostly driven by the fact that employees consider their supervisors as agents working together on behalf of organization (Shanock \& Eisenberger, 2006). Employees may provide supervisor support by bringing out better performance so as to return the favour (Zhou, Martinez, Ferreira, 2016). Yoon and Lim (1999) define supervisor support as "her/his main and chief supervisor support of the employee being the central and important point". 
Supervisors are expected to provide feedback and support in the accomplishment of various tasks to employees (Shanock \& Eisenberger, 2006). Therefore, it is crucial for social recognition, performance feedback, and development of competencies (Weigl et al., 2016). Basic argument of this study relies on former researches (Maertz, Griffeth, Campbell, \& Allen, 2007; Zhou et al., 2016) that the employees' perceptions and behaviours about their supervisors can influence their organizational job outcomes as supported by social exchange theory (Blau, 1964). Inadequate level of supervisor support may divert them towards deviant behaviour which can negatively influence the welfare of firm and encourage withdrawal behaviours (Khan et al., 2015; Menguc, Auh, Fisher, \& Haddad, 2013).

\section{Subjective Vitality}

The concept of vitality has been developed within the self-determination theory (Ak1n, 2012). Researches on vitality often distinguished as subjective and objective vitality (Abrams et al., 2009; Barker \& Gils, 2004, 79). Subjective vitality, explained as the favourable feeling of having energy accessible to the self, is a major and dynamic construct (Nix, Ryan, Manly, \& Deci, 1999). Subjective vitality was explained and carefully considered by Ryan and Frederick (1997) as the subjective knowledge and skill of being full of energy and alive (Bostic, Rubio, \& Hood, 2000). It combines the psychological energy available to an individual that reflects well-being. It is known as promoting behaviours that support a healthy lifestyle (Niemiec et al., 2010). Ryan and Frederick (1997) stated that in both the physical and mental sense, vitality refers to a feeling of aliveness. The word itself is derived from vita or "life" such that one who is vital feels alive, enthusiastic, and spirited. In the physical sense, vitality can be described as feeling healthy, qualified, and energetic (Kark \& Carmeli, 2009). Employee vitality, which is defined as a powerful and effective phenomenon, relevant to both mental and physical features of operating refers to a person who is vital as energetic, feeling alive, and fully functioning (Ryan \& Bernstein, 2004). It is often declared that subjective vitality, despite its importance, has been examined in limited studies in organizational aspect (Kark \& Carmeli, 2009).

\section{Research Goal and the Theoretical Model}

The purpose of this study is to determine the predictors of turnover intention. In this respect, the effect of burnout on turnover intention and the moderator roles of subjective vitality and supervisor support on this relationship was investigated. According to the theoretical background and robust rationales, the developed conceptual model is presented in Figure 1.

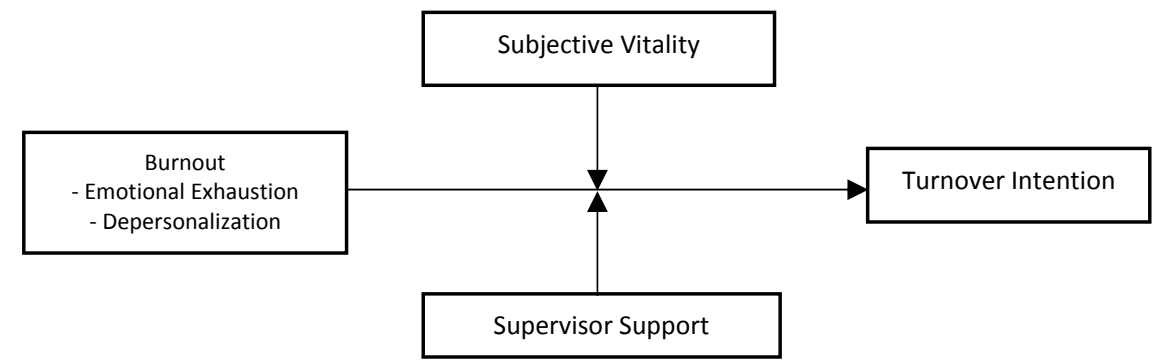

Figure 1. Conceptual model 


\section{Research Hypotheses}

The following research hypotheses guided the study.

$\mathbf{H}_{1 \mathbf{a}}$ : Emotional exhaustion positively affects turnover intention.

$\mathbf{H}_{\mathbf{1 b}}$ : Depersonalization positively affects turnover intention.

$\mathbf{H}_{2 \mathbf{a}}$ : Subjective vitality moderates the relationship between emotional exhaustion and turnover intention.

$\mathbf{H}_{2 \mathbf{b}}$ : Subjective vitality moderates the relationship between depersonalization and turnover intention.

It follows that:

$\mathbf{H}_{3 \mathbf{a}}$ : Supervisor support moderates the relationship between emotional exhaustion and turnover intention.

$\mathbf{H}_{\mathbf{3} \mathbf{b}}$ : Supervisor support moderates the relationship between depersonalization and turnover intention.

\section{Method}

The sample of this study consists of 295 health employees working in Istanbul. To collect data survey method was used. Participants were chosen according to convenience sampling method. The data was gathered using face to face interview. Accordingly, 350 questionnaires were distributed and 310 were returned, and 15 questionnaires were eliminated because of the missing information. Therefore, a total of 295 responses (\%84 response rate) were excluded. The majority of the respondents were 25-35 age group (\%59.3); following this, 69 percent were female. Regarding the level of education, $\% 61.9$ were graduated; moreover, $\% 52.2$ were single and $\% 60.1$ of the participants had 1-10 years of experience.

According to the study, burnout was measured with 14-item scale (9-item scale for emotional exhaustion and the other 6-item item for depersonalization). The scale was developed by Maslach and Jackson (1981). The scale consists of four sub-dimensions; the two sub-dimensions, namely emotional exhaustion and depersonalization was used in accordance with the scope of the study. Subjective vitality was measured with Ryan and Frederick's (1997) 7-item scale and supervisor support was measured with Yoon and Thye's (2000) 3-item scale. Lastly, turnover intention was measured with Mobley, Griffeth, Hand, and Meglino's (1979) 3item scale. A 5-point response format was used to measure of all constructs, ranging from " 1 = strongly disagree" to " 5 = strongly agree".

\section{Results}

To test the hypotheses, a series of preliminary analysis were used. Firstly, to test the construct validity, exploratory factor analysis was conducted. Next, to test the internal consistency, Cronbach's Alpha test was used. Then, bivariate correlation analysis was applied to determine the direction and significance of the relations. After, The PROCESS was used to test the hypothesized direct and interactional causal effects.

\section{Factor Analysis}

To test the construct validity, exploratory factor analysis was conducted. According to the test results, the five factor structure namely emotional exhaustion, depersonalization, subjective 
vitality, supervisor support, and turnover intention showed consistency with our proposed research model. Varimax rotation method was used as extraction method. Factor analysis results are presented in Table 1.

Table 1

Factor Analysis Results

\begin{tabular}{|c|c|c|c|c|c|}
\hline \multirow{2}{*}{ Items } & \multicolumn{5}{|c|}{ Factor Loadings } \\
\hline & EE & SV & DP & SS & TI \\
\hline EE 4: Working with people all day is really a strain for me. & 0.83 & & & & \\
\hline EE 2: I feel used up at the end of the workday & 0.82 & & & & \\
\hline EE 3: I feel fatigued when I get up in the morning and have to face another day on the job & 0.82 & & & & \\
\hline EE 5: I feel burned out from my work. & 0.79 & & & & \\
\hline EE 1: I feel emotionally drained from my work & 0.78 & & & & \\
\hline EE 7: I feel I'm working too hard on my job. & 780 & & & & \\
\hline EE 6: I feel frustrated by my job. & 0.70 & & & & \\
\hline EE 8: Working with people directly puts too much stress on me. & 0.67 & & & & \\
\hline EE 9: I feel like I'm at the end of my rope. & 0.58 & & & & \\
\hline SV 7: I feel energized. & & 0.90 & & & \\
\hline SV 6: I nearly always feel alert and awake. & & 0.88 & & & \\
\hline SV 4: I have energy and spirit. & & 0.83 & & & \\
\hline SV 5: I look forward to each new day. & & 0.83 & & & \\
\hline SV 1: I feel alive and vital. & & 0.80 & & & \\
\hline SV 3: Sometimes I feel so alive I just want to burst. & & 0.73 & & & \\
\hline DP19: I've become more callous toward people since I took this job. & & & 0.78 & & \\
\hline DP18: I feel I treat some recipients as if they were impersonal 'objects'. & & & 0.77 & & \\
\hline DP21: I don’t really care what happens to some recipients. & & & 0.77 & & \\
\hline DP22: I feel recipients blame me for some of their problems. & & & 0.74 & & \\
\hline DP20: I worry that this job is hardening me emotionally & & & 0.66 & & \\
\hline SS2: My supervisor is willing to listen to work related problems. & & & & 0.92 & \\
\hline SS3. My supervisor can be relied on when things get difficult at work. & & & & 0.87 & \\
\hline SS1: My supervisor is very concerned about the welfare of those under him or her. & & & & 0.86 & \\
\hline TI 3: I will leave this institution/firm at the first opportunity. & & & & & 0.84 \\
\hline TI 1: I frequently think about quitting this institution & & & & & 0.82 \\
\hline TI 2: I am actively searching for another job. & & & & & 0.80 \\
\hline Cronbach's Alpha & $\alpha=.93$ & $\alpha=.92$ & $\alpha=.87$ & $\alpha=.71$ & $\alpha=.88$ \\
\hline Explained Variance & $\% 22.56$ & $\% 17.00$ & $\% 13.40$ & $\% 9.90$ & $\% 9.12$ \\
\hline Total Variance Explained & & & $\% 71.996$ & & \\
\hline $\begin{array}{l}\mathrm{KMO}=0.09, \text { Barlett's Test of Sphericity }=5135.61(325) \mathrm{p}<0.00 \\
\text { Rotation converged in } 6 \text { iterations. }\end{array}$ & & & & & \\
\hline
\end{tabular}

\section{Correlations and Descriptive Statistics}

Mean, standard deviation, Cronbach's alpha reliability coefficient, and correlation levels of all the variables are exhibited in Table 2.

Table 2

Correlations, Means, Standard Deviations, and Reliability Levels of Variables

\begin{tabular}{llllllll}
\hline Variable & Mean & S.D. & EE & DP & SV & SS & TI \\
\hline Emotional Exhaustion & 2.37 & 1.08 & $(0.93)$ & & & & \\
Depersonalization & 3.11 & 1.04 & $0.59^{* *}$ & $(0.92)$ & & & \\
Subjective Vitality & 3.27 & 0.95 & -0.10 & $-0.24^{* *}$ & $(0.87)$ & & \\
Supervisor Support & 3.28 & 1.09 & -0.06 & $-0.23^{* *}$ & $0.31^{* *}$ & $(0.71)$ & $(0.88)$ \\
Turnover Intention & 2.73 & 1.18 & $0.44^{* *}$ & $0.45^{* *}$ & $-0.16^{* *}$ & $-0.27^{* *}$ & \\
\hline
\end{tabular}

Notes: (a) EE: Emotional exhaustion, DP: Depersonalization, SV: Subjective vitality, SS: Supervisor support; TI: Turnover intention, (b)**p $<0,01$; (c) Cronbach's Alpha coefficients are presented in parenthesis. 
According to Table 2, there is a positive and significant relationships between depersonalization and emotional exhaustion $(\mathrm{r}=0.59)$, turnover intention and emotional exhaustion $(\mathrm{r}=0.44)$, turnover intention and depersonalization $(\mathrm{r}=0.45)$, and supervisor support and subjective vitality $(\mathrm{r}=0.31)$. Additionally, there are also some negative and significant relationships between subjective vitality and depersonalization $(\mathrm{r}=-0.24)$, supervisor support and depersonalization $(\mathrm{r}=-0.23)$, turnover intention and subjective vitality, and turnover intention and supervisor support $(\mathrm{r}=-0.27)$.

\section{Moderator Role of Subjective Vitality}

To test the direct and interactional effects, PROCESS that is a SPSS macro was used (Hayes, 2013). This macro enables to test complex relations such as moderated mediation, tree-way interaction, and mediated moderation. It is also useful for reaching more information about some simple moderation or mediation analysis. The results of $\mathrm{H}_{1 \mathrm{a}}$ and $\mathrm{H}_{2 \mathrm{a}}$ are presented in Table 3 which shows the moderating effects of subjective vitality on the emotional exhaustionturnover intention relationship.

Table 3

Moderating Effects of Subjective Vitality on the Emotional Exhaustion-Turnover Intention Relationship

\begin{tabular}{|c|c|c|c|c|}
\hline \multicolumn{5}{|c|}{ Regression Results for Conditional Effect of Subjective Vitality } \\
\hline Predictor & $\beta$ & SE & $\mathrm{t}$ & $\mathrm{p}$ \\
\hline \multicolumn{5}{|c|}{ Turnover Intention } \\
\hline Constant & 2.77 & 0.06 & 44.20 & $0.00 * * * *$ \\
\hline Emotional Exhaustion & 0.48 & 0.06 & 7.99 & $0.00 * * * *$ \\
\hline Subjective Vitality & -0.10 & 0.06 & -1.54 & 0.12 n.s. \\
\hline $\begin{array}{l}\text { Emotional Exhaustion x Subjective } \\
\text { Vitality }\end{array}$ & 0.13 & 0.05 & 2.58 & $0.01 *$ \\
\hline Subjective Vitality & Interactional Effect & SE & $\mathrm{t}$ & $\mathrm{p}$ \\
\hline \multicolumn{5}{|c|}{ Conditional Indirect Effect at Subjective Vitality $=\mathrm{M} \pm 1 \mathrm{SD}$} \\
\hline M - 1 SD (-0.95) Low & 0.35 & 0.08 & 4.31 & $0.00^{* * *}$ \\
\hline $\mathrm{M}(0.000)$ Medium & 0.48 & 0.06 & 7.99 & $0.00 * * * *$ \\
\hline $\mathrm{M}+1 \mathrm{SD}(0.95) \mathrm{High}$ & 0.61 & 0.07 & 8.26 & $0.00 * * * *$ \\
\hline \multirow[t]{2}{*}{ Model Summary } & $\mathrm{R}$ & R-sq & $\mathrm{F}$ & $\mathrm{p}$ \\
\hline & 0.48 & 0.23 & 28.648 & $0.00 * * * *$ \\
\hline \multirow[t]{2}{*}{ R-sq Increase due to Interaction } & R-sq change & $\mathrm{F}$ & df & $\mathrm{p}$ \\
\hline & 0.01 & 6.67 & 287 & $0.01 *$ \\
\hline
\end{tabular}

As can be seen in Table 3, emotional exhaustion positively affects turnover intention ( $\beta=0.48$; $\mathrm{t}=7.99 ; \mathrm{p}<0.00)$; thus, $\mathrm{H}_{1 \mathrm{a}}$ is supported. Also, the effect of subjective vitality on turnover intention is not significant $(\beta=-0.10 ; \mathrm{t}=-1.54 ; \mathrm{p}=1232 \mathrm{n} . \mathrm{s}$.). Additionally, the moderating effect of subjective vitality on the relationship between emotional exhaustion and turnover intention is significant $(\beta=0.13 ; \mathrm{t}=2.58 ; \mathrm{p}<0.01)$. Moreover, according to Table 3 , the three-level (low, medium, and high) of subjective vitality positively affects the direct relationship between emotional exhaustion and turnover intention. In other words, it is easy to say that as the level of subjective vitality increases, the effects of it on the direct relationship between emotional exhaustion and turnover intention also increases. According to these results, $\mathrm{H} 2 \mathrm{a}$ is also supported. Table 4 shows the moderating effects of subjective vitality on the depersonalizationturnover intention relationship. 
Moderating Effects of Subjective Vitality on the Depersonalization-Turnover Intention Relationship Regression Results for Conditional Effect of Subjective Vitality

\begin{tabular}{|c|c|c|c|c|}
\hline Predictor & $\beta$ & SE & $\mathrm{t}$ & $\mathrm{p}$ \\
\hline \multicolumn{5}{|c|}{ Turnover Intention } \\
\hline Constant & 2.74 & 0.06 & 44.99 & $0.00 * * * *$ \\
\hline Depersonalization & 0.42 & 0.05 & 7.24 & $0.00^{* * * *}$ \\
\hline Subjective Vitality & 0.20 & 0.06 & 3.07 & $0.00^{* *}$ \\
\hline Depersonalization x Subjective Vitality & 0.17 & 0.05 & 3.20 & $0.00^{* *}$ \\
\hline Subjective Vitality & Interactional Effect & SE & $\mathrm{t}$ & $\mathrm{p}$ \\
\hline \multicolumn{5}{|c|}{ Conditional Indirect Effect at Subjective Vitality $=\mathrm{M} \pm 1 \mathrm{SD}$} \\
\hline M - 1 SD (-0.95) Low & 0.26 & 0.08 & 2.99 & $0.00^{* * *}$ \\
\hline $\mathrm{M}(0.000)$ Medium & 0.42 & 0.05 & 7.24 & $0.00^{* * * *}$ \\
\hline $\mathrm{M}+1 \mathrm{SD}(0.95) \mathrm{High}$ & 0.58 & 0.06 & 8.71 & $0.00^{* * * *}$ \\
\hline \multirow[t]{2}{*}{ Model Summary } & $\mathrm{R}$ & R-sq & $\mathrm{F}$ & $\mathrm{p}$ \\
\hline & 0.48 & 0.24 & 30.07 & $0.00^{* * * *}$ \\
\hline \multirow[t]{2}{*}{ R-sq Increase due to Interaction } & R-sq Change & $\mathrm{F}$ & df & $\mathrm{p}$ \\
\hline & 0.02 & 10.28 & 286 & $0.00 *$ \\
\hline
\end{tabular}

As Table 4 exhibits, depersonalization positively affects turnover intention $(\beta=0.42 ; t=7.24$; $\mathrm{p}<0.00$ ); thus, $\mathrm{H}_{1 \mathrm{~b}}$ is supported. Moreover, the effect of subjective vitality on turnover intention is positive and significant $(\beta=0.20 ; \mathrm{t}=-3.07 ; \mathrm{p}<0023)$. Additionally, the moderating effect of subjective vitality on the relationship between depersonalization and turnover intention is significant $(\beta=0.17 ; \mathrm{t}=3.20 ; \mathrm{p}<0.00)$. In addition, according to Table 4 , the three-level (low, medium, and high) of subjective vitality positively affects the direct relationship between depersonalization and turnover intention. In other words, as the level of subjective vitality increases, the effects of it on the direct relationship between depersonalization and turnover intention increases as well. According to these results, $\mathrm{H}_{2 \mathrm{~b}}$ is also supported.

\section{Moderator Role of Supervisor Support}

Table 5 presents the moderating effects of supervisor support on the emotional exhaustionturnover intention relationship.

Table 5

Moderating Effects of Supervisor Support on the Emotional Exhaustion-Turnover Intention Relationship

\begin{tabular}{|c|c|c|c|c|}
\hline \multicolumn{5}{|c|}{ Regression Results for Conditional Effect of Supervisor Support } \\
\hline Predictor & $\beta$ & SE & $\mathrm{t}$ & $\mathrm{p}$ \\
\hline \multicolumn{5}{|c|}{ Turnover Intention } \\
\hline Constant & 2.77 & 0.06 & 45.58 & $0.00 * * * *$ \\
\hline Emotional Exhaustion & 0.44 & 0.05 & 7.59 & $0.00 * * * *$ \\
\hline Supervisor Support & -0.23 & 0.05 & -4.07 & $0.00 * *$ \\
\hline Emotional Exhaustion x Supervisor Support & 0.18 & 0.04 & 3.68 & $0.00 * * *$ \\
\hline Subjective Support & Interactional Effect & SE & $\mathrm{t}$ & $\mathrm{p}$ \\
\hline \multicolumn{5}{|c|}{ Conditional Indirect Effect at Supervisor Support $=\mathrm{M} \pm 1 \mathrm{SD}$} \\
\hline $\mathrm{M}-1 \mathrm{SD}(-1.09)$ Low & 0.24 & 0.08 & 2.98 & $0.00^{* *}$ \\
\hline $\mathrm{M}(0.000)$ Medium & 0.44 & 0.05 & 7.59 & $0.00 * * * *$ \\
\hline $\mathrm{M}+1 \mathrm{SD}(1.09) \mathrm{High}$ & 0.64 & 0.07 & 8.54 & $0.00 * * * *$ \\
\hline Model Summary & $\mathrm{R}$ & R-sq & $\mathrm{F}$ & $\mathrm{p}$ \\
\hline & 0.52 & 0.27 & 35.57 & $0.00^{* * * *}$ \\
\hline \multirow[t]{2}{*}{ R-sq Increase due to Interaction } & R-sq Change & $\mathrm{F}$ & df & $\mathrm{p}$ \\
\hline & 0.03 & 13.55 & 286 & $0.00 *$ \\
\hline
\end{tabular}


As Table 5 clearly indicates, emotional exhaustion positively affects turnover intention ( $\beta=0.44 ; \mathrm{t}=7.59 ; \mathrm{p}<0.00$ ); thus, $\mathrm{H}_{1 \mathrm{a}}$ is supported. Moreover, the effect of supervisor support on turnover intention is negative and significant $(\beta=-0.23 ; \mathrm{t}=-4.07 ; \mathrm{p}<001)$. Additionally, the moderating effect of supervisor support on the relationship between emotional exhaustion and turnover intention is significant $(\beta=0.18 ; \mathrm{t}=3.68 ; \mathrm{p}<0.00)$. In addition, as seen from Table 5 , the three-level (low, medium, and high) of supervisor support positively affects the direct relationship between emotional exhaustion and turnover intention. In other words, as the level of supervisor support increases, the effects of it on the direct relationship between emotional exhaustion and turnover intention also increases. According to these results H3a also supported. Table 6 represents the moderating effects of supervisor support on depersonalization-turnover intention relationship.

Table 6

Moderating Effects of Supervisor Support on Depersonalization-Turnover Intention Relationship

\begin{tabular}{|c|c|c|c|c|}
\hline \multicolumn{5}{|c|}{ Regression Results for Conditional Effect of Supervisor Support } \\
\hline Predictor & $\beta$ & $\mathrm{SE}$ & $\mathrm{t}$ & $\mathrm{p}$ \\
\hline \multicolumn{5}{|c|}{ Turnover Intention } \\
\hline Constant & 2.73 & 0.05 & 47.69 & $0.00 * * * *$ \\
\hline Depersonalization & 0.42 & 0.05 & 7.76 & $0.00 * * * *$ \\
\hline Supervisor Support & -0.31 & 0.05 & -5.86 & $0.00 * * * *$ \\
\hline Depersonalization x Supervisor Support & 0.22 & 0.04 & 4.88 & $0.00 * * * *$ \\
\hline Subjective Support & Interactional Effect & SE & $\mathrm{t}$ & $\mathrm{p}$ \\
\hline \multicolumn{5}{|c|}{ Conditional Indirect Effect at Supervisor Support $=\mathrm{M} \pm 1 \mathrm{SD}$} \\
\hline M - 1 SD (-1.09) Low & 0.17 & 0.08 & 2.22 & $0.02 *$ \\
\hline M (0.000) Medium & 0.42 & 0.05 & 7.76 & $0.00 * * * *$ \\
\hline $\mathrm{M}+1 \mathrm{SD}$ (1.09) High & 0.66 & 0.06 & 10.01 & $0.00 * * * *$ \\
\hline \multirow[t]{2}{*}{ Model Summary } & $\mathrm{R}$ & R-sq & $\mathrm{F}$ & $\mathrm{p}$ \\
\hline & 0.56 & 0.32 & 44.80 & $0.00 * * * *$ \\
\hline \multirow[t]{2}{*}{$\mathrm{R}$-sq Increase due to Interaction } & R-sq Change & $\mathrm{F}$ & df & $\mathrm{p}$ \\
\hline & 0.05 & 23.82 & 285 & $0.00 * * * *$ \\
\hline
\end{tabular}

According to Table 6 , depersonalization positively affects turnover intention $(\beta=0.42$; $\mathrm{t}=7.76 ; \mathrm{p}<0.00$ ); therefore, $\mathrm{H}_{1 \mathrm{~b}}$ is supported. Following this, the effect of supervisor support on turnover intention is negative and significant $(\beta=-0.23 ; \mathrm{t}=-4.07 ; \mathrm{p}<001)$. Additionally, the moderating effect of supervisor support on the relationship between emotional exhaustion and turnover intention is significant $(\beta=0.18 ; \mathrm{t}=3.68 ; \mathrm{p}<0.001)$. Moreover, the three-level (low, medium, and high) of supervisor support positively affects the direct relationship between emotional exhaustion and turnover intention. In other words, as the level of supervisor support increases, the effects of it on the direct relationship between emotional exhaustion and turnover intention also increases. According to these results, $\mathrm{H}_{3 \mathrm{~b}}$ is also supported.

\section{Discussion and Conclusion}

Supervisors are persons in the organization that serve as valuable resources by supporting employees coping with burnout problems. Following this, they are also able to influence the withdrawal behaviour of employees. Emotional exhaustion and depersonalization are the negative outcomes of stress that the employees cope with during performing their tasks. Generally speaking, this research is based on the argument that burnout predicts turnover 
intention among nurses and this relation is buffered by supervisor support and subjective vitality. Burnout is the focus of our research for several reasons: First, the negative effects of burnout on employees' turnover intention can lead to substantial costs caused by absenteeism and reduced productivity. Second, an understanding of the role of burnout may help to guide management in reducing its harmful effects. Supervisor support and subjective vitality are the factors that positively influence employee well-being while negatively and strongly associates with employee burnout syndrome. Therefore, it is necessary for supervisors and managers to provide adequate support to their employees to help them develop their confidence to fulfil their work goals.

As understood from the findings, consistent with the literature (Cropanzano et al., 2003; Fogarty et al., 2000; Jones et al., 2010; Leiter Michael \& Maslach 2009), burnout is one of the important drivers of turnover intention. To this end, the positive causal relationship between burnout and turnover intention supports this notion. Interestingly, the strength of the relationship between burnout and turnover intention is stronger when the level of employees' supervisor support and subjective vitality are high. These relationships could be explained considering the supervisor's empathy with his/her followers. Given the sample characteristic of this study and the importance of health sector employees in the human life, this finding is satisfactory. In other words, one could easily predict that supervisors in the health sector treat their exhausted employees with the paternalistic approach to deal with their unhappiness at the expense of turnover intention. This approach enables an organizational milieu, where the employee related counterproductive workplace behaviors or casualties could be prevented with a proactive manner. Correspondingly, as aforementioned, subjective vitality as one of the positive feelings of individuals constitutes the base of healthy lifestyle (Niemiec et al., 2010). As might be expected, employees with high-level of subjective vitality are more prone to avoid undesired psychological or other unhealthy conditions to pursue their wellbeing. In this respect, it is not surprising that employees with high-level of subjective vitality are more prone to turnover intention.

Taken together, when the implications based on the findings are considered, it can be inferred that due to the detrimental consequences of burnout on employee turnover intention, it is critical for organizations to implement effective policies to prevent employees from experiencing burnout. In addition, the support of supervisor can be a major support for employee-supervisor relation, since powerful relationship between a supervisor and a subordinate tends to predict the level of trust, respect, and obligation that a subordinate receives from a supervisor. Furthermore, the contribution of subjective vitality to employee well-being is congruent with the leader-member exchange theory; because subjective vitality provides positive energy to employee that reflects his/her well-being, it can promote behaviours that support a healthy lifestyle, strengthens the social relations within the organization, and reduces the negative impact of burnout behaviour and its consequence on increased turnover intention. 


\section{References}

Abrams, J. R., Barker, V., \& Giles, H. (2009). An examination of the validity of the Subjective Vitality Questionnaire. Journal of Multilingual \& Multicultural Development, 30(1), 59-72.

Ak1n, A. (2012). The relationships between Internet addiction, subjective vitality, and subjective happiness. Cyberpsychology, Behavior, \& Social Networking, 15(8), 404-410.

Al-Dubai, S. A. R., \& Rampal, K. G. (2010). Prevalence and associated factors of burnout among doctors in Yemen. Journal of Occupational Health, 52(1), 58-65.

Allen, T. D., \& Kiburz, K. M. (2012). Trait mindfulness and work-family balance among working parents: The mediating effects of vitality and sleep quality. Journal of Vocational Behavior, 80(2), 372-379.

Arı, G. S., Bal, H., \& Bal, E. Ç. (2010). İşe Bağlılı̆̆n Tükenmişlik ve İşten Ayrılma Niyeti İlişkisindeki Aracılık Etkisi: Yatırım Uzmanları Üzerinde Bir Araştırma. Süleyman Demirel Üniversitesi İktisadi ve İdari Bilimler Fakültesi Dergisi, 15(3), 143-166.

Ashtari, Z., Farhady, Y., \& Khodaee, M. R. (2009). Relationship between job burnout and work performance in a sample of Iranian mental health staff. African Journal of Psychiatry, 12(1), 71-74.

Babin, B. J., \& Boles, J. S. (1996). The effects of perceived co-worker involvement and supervisor support on service provider role stress, performance and job satisfaction. Journal of Retailing, 72(1), 57-75.

Barker, V., \& Giles, H. (2004). English-only policies: Perceived support and social limitation. Language \& Communication, 24(1), 77-95.

Blanch, A., \& Aluja, A. (2012). Social support (family and supervisor), work-family conflict, and burnout: Sex differences. Human Relations, 65(7), 811-833.

Blau, P. M. (1964). Exchange and power in social life. Piscataway, NJ: Transaction Publishers.

Bogaert, P., Clarke, S., Willems, R., \& Mondelaers, M. (2013). Nurse practice environment, workload, burnout, job outcomes, and quality of care in psychiatric hospitals: A structural equation model approach. Journal of Advanced Nursing, 69(7), $1515-1524$.

Bostic, T. J., Rubio, D. M., \& Hood, M. (2000). A validation of the subjective vitality scale using structural equation modeling. Social Indicators Research, 52(3), 313-324.

Charoensukmongkol, P., Moqbel, M., \& Gutierrez-Wirsching, S. (2016). The role of coworker and supervisor support on job burnout and job satisfaction. Journal of Advances in Management Research, 13(1), 4-22.

Choi, S., Cheong, K., \& Feinberg, R. A. (2012). Moderating effects of supervisor support, monetary rewards, and career paths on the relationship between job burnout and turnover intentions in the context of call centers. Managing Service Quality: An International Journal, 22(5), 492-516.

Cropanzano, R., \& Mitchell, M. S. (2005). Social exchange theory: An interdisciplinary review. Journal of Management, $31(6), 874-900$.

Cropanzano, R., Rupp, D. E., \& Byrne, Z. S. (2003). The relationship between emotional exhaustion to work attitudes, job performance, and organizational citizenship behaviors. Journal of Applied Psychology, 88(1), 160-169.

Eisenberger, R., Stinglhamber, F., Vandenberghe, C., Sucharski, I. L., \& Rhoades, L. (2002). Perceived supervisor support: contributions to perceived organizational support and employee retention. Journal of Applied Psychology, 87(3), 565-573.

Fogarty, T. J., Jagdip, S., Gary, K. R., \& Ronald, K. M. (2000). Antecedents and consequences of burnout in accounting: Beyond the role stress model. Behavioral Research in Accounting, 12, 31-68.

Gilbreath, B., \& Benson, P. G. (2004). The contribution of supervisor behaviour to employee psychological well-being. Work \& Stress, 18(3), 255-266.

Han, S. J., Bonn, M. A., \& Cho, M. (2016). The relationship between customer incivility, restaurant frontline service employee burnout and turnover intention. International Journal of Hospitality Management, 52, 97-106.

Hayes, A. F. (2013). Introduction to mediation, moderation, and conditional process analysis: A regression-based approach. New York, NY: Guilford Press.

Himle, D. P., Jayaratne, S., \& Thyness, P. A. (1989). The buffering effects of four types of supervisory support on work stress. Administration in Social Work, 13(1), 19-34.

Huang, I. C., Chuang, C. H. J., \& Lin, H. C. (2003). The role of burnout in the relationship between perceptions of organizational politics and turnover intentions. Public Personnel Management, 32(4), 519-531.

Jones, A., Norman, C. S., \& Weir, B. (2010). Healthy lifestyle as a coping mechanism for role stress in public accounting. Behavioral Research in Accounting, 22(1), 21-41. 
Kalliath, T. J., \& Beck, A. (2001). Is the path to burnout and turnover paved by a lack of supervisory support? A structural equations test. New Zealand Journal of Psychology, 30(2), 72-78.

Karasek, R. A., Triantis, K. P., \& Chaudhry, S. S. (1982). Coworker and supervisor support as moderators of associations between task characteristics and mental strain. Journal of Organizational Behavior, 3(2), 181-200.

Kark, R., \& Carmeli, A. (2009). Alive and creating: The mediating role of vitality and aliveness in the relationship between psychological safety and creative work involvement. Journal of Organizational Behavior,30(6), 785-804.

Keel, P. (1993). Psychological stress caused by work: burnout syndrome. Soz Praventivmed, 2, 131-132.

Khan, S. I., Mahmood, A., Kanwal, S., \& Latif, Y. (2015). How perceived supervisor support effects workplace deviance? Mediating role of perceived organizational support. Pakistan Journal of Commerce \& Social Sciences, 9(3), 940-967.

Kickul, J., \& Posig, M. (2001). Supervisory emotional support and burnout: An explanation of reverse buffering effects. Journal of Managerial Issues, 13(3), 328-344.

Kim, H., \& Lee, S. Y. (2009). Supervisory communication, burnout, and turnover intention among social workers in health care settings. Social Work in Health Care, 48(4), 364-385.

Kim, H., \& Stoner, M. (2008). Burnout and turnover intention among social workers: Effects of role stress, job autonomy and social support. Administration in Social Work, 32(3), 5-25.

Kirmeyer, S. L., \& Dougherty, T. W. (1988). Work load, tension, and coping: Moderating effects of supervisor support. Personnel Psychology, 41(1), 125-139.

Lasalvia, A., Bonetto, C., Bertani, M., Bissoli, S., Cristofalo, D., Marrella, G., ... \& Ruggeri, M. (2009). Influence of perceived organisational factors on job burnout: survey of community mental health staff. The British Journal of Psychiatry, 195(6), $537-544$

Lazaro, C., Shinn, M. \& Robinson, P.E. (1984). Burnout, job performance, and job withdrawal behaviors. Journal of Health \& Human Resources Administration, 7, 213-234.

Lee, R. T. \& Ashforth, B. E. (1996). A meta-analytic examination of the correlates of the three dimensions of job burnout. Journal of Applied Psychology, 81(2), 123-33.

Leither Michael, P., \& Maslach, C. (2009). Nurse Turnover: The mediating role of burnout. Journal of Nursing Management, $17,331-339$

Lin, Q. H., Jiang, C. Q., \& Lam, T. H. (2013). The relationship between occupational stress, burnout, and turnover intention among managerial staff from a Sino-Japanese joint venture in Guangzhou, China. Journal of Occupational Health, 55, $458-467$.

Lu, A. C. C., \& Gursoy, D. (2016). Impact of job burnout on satisfaction and turnover intention do generational differences matter? Journal of Hospitality \& Tourism Research, 40(2), 210-235.

Maertz, C. P., Griffeth, R. W., Campbell, N. S., \& Allen, D. G. (2007). The effects of perceived organizational support and perceived supervisor support on employee turnover. Journal of Organizational Behavior, 28(8), 1059-1075.

Maslach, C., \& Jackson, S. E. (1981). The measurement of experienced burnout. Journal of Organizational Behavior, 2(2), 99-113.

Menguc, B., Auh, S., Fisher, M., \& Haddad, A. (2013). To be engaged or not to be engaged: The antecedents and consequences of service employee engagement. Journal of Business Research, 66(11), 2163-2170.

Mobley, W. H., Griffeth, R. W., Hand, H. H., \& Meglino, B. M. (1979). Review and conceptual analysis of the employee turnover process. Psychological Bulletin, 86(3), 493-522.

Niemiec, C. P., Ryan, R. M., Patrick, H., Deci, E. L., \& Williams, G. C. (2010). The energization of health-behavior change: examining the associations among autonomous self-regulation, subjective vitality, depressive symptoms, and tobacco abstinence. The Journal of Positive Psychology, 5(2), 122-138.

Nix, G. A., Ryan, R. M., Manly, J. B., \& Deci, E. L. (1999). Revitalization through self-regulation: The effects of autonomous and controlled motivation on happiness and vitality. Journal of Experimental Social Psychology, 35(3), 266-284.

O'Driscoll, M. P., Poelmans, S., Spector, P. E., Kalliath, T., Allen, T. D., Cooper, C. L., \& Sanchez, J. I. (2003). Familyresponsive interventions, perceived organizational and supervisor support, work-family conflict, and psychological strain. International Journal of Stress Management, 10(4), 326-344.

Özler, D. E., \& Atalay, C. G. (2011). A research to determine the relationship between organizational cynicism and burnout levels of employees in health sector. Business and Management Review, 1(4), 26-38.

Payne, N. (2001). Occupational stressors and coping as determinants of burnout in female hospice nurses. Journal of Advanced Nursing, 33(3), 396-405. 
Pienaar, J., \& Willemse, S. A. (2008). Burnout, engagement, coping and general health of service employees in the hospitality industry. Tourism Management, 29(6), 1053-1063.

Porter, L. W., Steers, R. M., Mowday, R. T., \& Boulian, P. V. (1973). Organizational commitment, job satisfaction, and turnover among psychiatric technicians. Journal of Applied Psychology, 59(5), 603-609.

Rhoades, L., \& Eisenberger, R. (2002). Perceived organizational support: A review of the literature. Journal of Applied Psychology, 87(4), 698-714.

Russo, J. A., \& Waters, L. E. (2006). Workaholic worker type differences in work-family conflict: The moderating role of supervisor support and flexible work scheduling. Career Development International, 11(5), 418-439.

Ryan, R. M., \& Frederick, C. (1997). On energy, personality, and health: Subjective vitality as a dynamic reflection of well-being. Journal of Personality, 65(3), 529-565.

Ryan, R. M., \& Bernstein, J. H. (2004). Vitality. In C. Peterson \& M. E. P. Seligman (Eds.), Character strengths and virtues: A handbook and classification (pp. 273-290). New York: Oxford University Press.

Salancik, G. R., \& Pfeffer, J. (1978). A social information processing approach to job attitudes and task design. Administrative Science Quarterly, 21(2), 224-253.

Shanock, L. R., \& Eisenberger, R. (2006). When supervisors feel supported: Relationships with subordinates' perceived supervisor support, perceived organizational support, and performance. Journal of Applied psychology, 91(3), 689-695.

Shimizu, T., Feng, Q., \& Nagata, S. (2005). Relationship between turnover and burnout among Japanese hospital nurses. Journal of Occupational Health, 47(4), 334-336.

Steel, R. P. (2002). Turnover theory at the empirical interface: Problems of fit and function. The Academy of Management Review, 27(3), 346-360.

Tarcan, G. Y., Tarcan, M., \& Top, M. (2016). An analysis of relationship between burnout and job satisfaction among emergency health professionals. Total Quality Management \& Business Excellence, 28(11/12), 1339-1356.

Tett, R. P., \& Meyer, J. P. (1993). Job satisfaction, organizational commitment, turnover intention, and turnover: Path analyses based on meta-analytic findings. Personnel Psychology, 46(2), 259-293.

Thomas, J., \& Griffin, R. (1983). The social information processing model of task design: A review of the literature. Academy of Management Review, 8(4), 672-682.

Toppinen-Tanner, S., Ojajärvi, A., Väänänen, A., Kalimo, R. \& Jäppinen, P. (2005). Burnout as a predictor of medically certified sick-leave absences and their diagnosed causes. Behavioral Medicine, 31(1), 18-27.

Tsai, F. J., Huang, W. L., Chan, C. C. (2009). Occupational stress and burnout of lawyers. Journal of Occupational Health, $51(5), 443-450$.

Tselebis, A., Moulou, A., \& Ilias, I. (2001). Burnout versus depression and sense of coherence: Study of Greek nursing staff. Nursing \& Health Sciences, 3(2), 69-71.

Turunç, Ö., \& Çelik, M. (2010). Algılanan örgütsel desteğin çalışanların iş-aile, aile-iş çatışması, örgütsel özdeşleşme ve işten ayrılma niyetine etkisi: Savunma sektöründe bir araştırma. Atatürk Üniversitesi Sosyal Bilimler Enstitüsü Dergisi, 14(1), $209-232$.

Weigl, M., Stab, N., Herms, I., Angerer, P., Hacker, W., \& Glaser, J. (2016). The associations of supervisor support and work overload with burnout and depression: A cross-sectional study in two nursing settings. Journal of Advanced Nursing, $72(8), 1-15$.

Wright, T. A., \& Cropanzano, R. (2000). Psychological well-being and job satisfaction a predictors of job performance. Journal of Occupational Health Psychology, 5(1), 84-94.

Yoon, J., \& Lim, J. C. (1999). Organizational support in the workplace: The case of Korean hospital employees. Human Relations, 52(7), 923-945.

Yoon, J., \& Thye, S. (2000). Supervisor support in the work place: Legitimacy and positive affectivity. The Journal of Social Psychology, 140(3), 295-316.

Zhou, Q., Martinez, L. F., Ferreira, A. I., \& Rodrigues, P. (2016). Supervisor support, role ambiguity and productivity associated with presenteeism: A longitudinal study. Journal of Business Research, 69(9), 3380-3387, 1-8. 